Article

\title{
Static and Dynamic Mechanical Properties of 3D Printed ABS as a Function of Raster Angle
}

\author{
Mateusz Galeja ${ }^{1}$, Aleksander Hejna ${ }^{2, *}$ (D) , Paulina Kosmela ${ }^{2}$ and Arkadiusz Kulawik ${ }^{1}$ \\ 1 Department of Material Engineering, Central Mining Institute, Pl. Gwarków 1, 40-166 Katowice, \\ Poland; mgaleja@gig.eu (M.G.); akulawik@gig.eu (A.K.) \\ 2 Department of Polymer Technology, Gdańsk University of Technology, Narutowicza 11/12, 80-233 Gdańsk, \\ Poland; paulina.kosmela@pg.edu.pl \\ * Correspondence: aleksander.hejna@pg.gda.pl
}

Received: 23 December 2019; Accepted: 7 January 2020; Published: 9 January 2020

\begin{abstract}
Due to the rapid growth of 3D printing popularity, including fused deposition modeling (FDM), as one of the most common technologies, the proper understanding of the process and influence of its parameters on resulting products is crucial for its development. One of the most crucial parameters of FDM printing is the raster angle and mutual arrangement of the following filament layers. Presented research work aims to evaluate different raster angles $\left(45^{\circ}, 55^{\circ}, 55^{\circ}, 60^{\circ}\right.$ and $90^{\circ}$ ) on the static, as well as rarely investigated, dynamic mechanical properties of 3D printed acrylonitrile butadiene styrene (ABS) materials. Configuration named $55^{\circ}$ was based on the optimal winding angle in filament-wound pipes, which provides them exceptional mechanical performance and durability. Also in the case of 3D printed samples, it resulted in the best impact strength, comparing to other raster angles, despite relatively weaker tensile performance. Interestingly, all 3D printed samples showed surprisingly high values of impact strength considering their calculated brittleness, which provides new insights into understanding the mechanical performance of 3D printed structures. Simultaneously, it proves that, despite extensive research works related to FDM technology, there is still a lot of investigation required for a proper understanding of this process.
\end{abstract}

Keywords: 3D printing; infill angle; mechanical performance; acrylonitrile butadiene styrene; impact strength

\section{Introduction}

Three-dimensional (3D) prototyping belongs to the most popular topics that have emerged recently. The technology of additive manufacturing and rapid prototyping enabled localization and personalization of production, offering new opportunities to produce small objects at a lower cost with properties difficult to obtain with former technologies, such as injection molding, turning, or milling [1]. Today, the main technologies used in 3D printing are stereolithography (SLA), selective laser sintering (SLS), laminated object manufacturing (LOM), and fused deposition modeling (FDM) [2].

From all 3D printing technologies mentioned above, the most accessible to the public is the FDM technique. FDM is a technology based on additive manufacturing where the plastic filament is being drawn to the extrusion nozzle by the knurled feeder. It allows controlling the material's flow on demand. Printing nozzle at specified temperature starts to melt and extrude small beads of provided thermoplastic material, simultaneously being moved at horizontal and vertical directions, which results in a layer-by-layer deposition. Each layer can be considered as a sliced horizontal cross-section of the final object. The process results in ready-to-use products, as the material hardens after the nozzle is being moved to another layer of the final product [3]. The described approach allows printing objects of any desired shape following computer-aided design (CAD) [4]. 
In comparison to conventional manufacturing processes used for thermoplastic materials, FDM printing creates near-net-shape components with over $90 \%$ material usage. Therefore, it can be considered an environmentally friendly process. Thanks to the use of this technology, production does not require expensive molds to create complex parts [5]. The traditional industrial approach to machining uses subtraction processing guided by computer numerical control (CNC). The main problem starts if the product is too complex for the subtraction processes (cannot meet the specifications and objectives of the product). Over time, the only solution was to increase the precision and complexity of technology. Conversely, additive manufacturing has advantages that subtraction processing lacks [6].

Increased demand for the use of additive manufacturing, as a tool to create functional end-use products, requires a better understanding of the FDM process [7]. Good understanding of various printing parameters and their impact on the structure of resulting products is a necessary step for improving their mechanical properties. Such an approach would enable the implementation of 3D printing into industrial practice at a wider scale and partial substitution of injection molding in applications, in which it is generating high production costs, simultaneously increasing the price of obtained products.

The structure of FDM printed objects consists of layers behaving similarly to laminate structures, which allows using laminate theories in the mechanical behavior of the parts [8]. Therefore, some insights related to the mechanical properties of materials could be transferred from other materials to 3D printing. A very interesting example is the case of filament-wound pipes. During their manufacturing, rotation angle at each side of the mandrel controls filament winding structure based on the winding angle. The resulting pattern can be presented by a regular diamond-shaped cell with a simple laminated $+\varphi /-\varphi$ fiber orientation [9]. In the case of these materials, a winding angle of $55^{\circ}$ (see Figure 1) provides the best mechanical performance, especially considering ring stiffness of the material, very important from a technological point of view $[10,11]$.

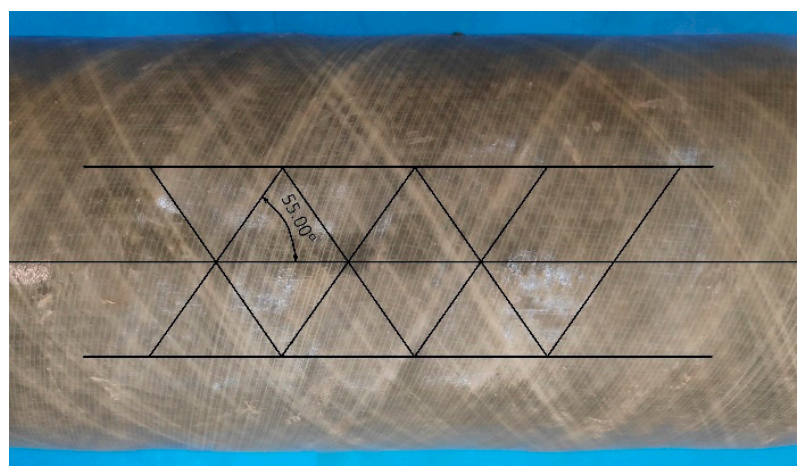

Figure 1. Alignment of fibers in filament-wound pipes.

The main goal of the presented research work is to analyze the influence of fill angle on tensile properties of 3D printed samples, as well as noticeably less frequently analyzed, impact performance and dynamic mechanical behavior to optimize further manufacturing processes [12]. Except for infill configurations conventionally analyzed in other research works, we aimed to investigate the configuration applied in the manufacturing of filament-wound pipes, which provides them the exceptional mechanical properties [13]. In most of the previous works, which investigate a similar topic of the raster angle, specimens were printed only in one direction without corresponding interlayer orientated in the right angle to the previous one, hence layers were deposited perpendicularly [14,15]. Noticeably fewer research works were related to investigations of the varying angle between alternating layers [16], and, to the best of our knowledge, no work has been published, in which $55^{\circ}$ configuration was analyzed, which have been repeatedly proven to provide exceptional properties in the case of filament-wound pipes $[17,18]$. Moreover, obtained materials were compared to injection molded 
specimens, as potentially 3D printing aims to replace injection molding, which requires noticeably more complex and more expensive machines.

\section{Materials and Methods}

\subsection{Materials}

Materials used for this study were commercial three types of acrylonitrile butadiene styrene filament differ in properties: ABS-X (black and white) named as 1B and 1W, ABS AT (natural white) named as $2 \mathrm{~W}$ provided by F3D Finnotech Sp. z o.o. (Katowice, Poland). According to the producer, ABS AT is dedicated for industrial and professional applications, it is characterized with higher thermal stability, and, therefore, it can be processed and work continuously at higher temperatures. ABS AT shows lower value of linear contraction, below $0.4 \%$, while, for ABS- $X$, it may reach $0.7 \%$. Moreover, comparing to ABS-X, it shows lower emissions of volatiles and absorption of moisture.

\subsection{Design}

Geometric models of test specimens necessary to perform tests have been made according to ISO 527-2-1A (Overall length $=170 \mathrm{~mm})$ and ISO $179-1(80 \times 10 \times 4 \mathrm{~mm}$, unnotched Charpy) standards with AUTODESK Inventor software (Inventor: 2018.3 Build: 284, Autodesk, Inc., San Rafael, CA, USA). Preparation of samples for 3D printing manufacturing purposes required making small corrections in specimen models by increasing thickness by $0.15 \mathrm{~mm}$, which corresponds with the thickness of the first layer used to attach the print to the printing table.

\subsection{Preparation of Samples}

Blixet B50-multi FDM 3D printer (Blixet Sp. z o.o., Sosnowiec, Poland) with build size $400 \times 400$ $\times 520 \mathrm{~mm}$ was used to print models from STL files. GCODE was generated by Repetier Host with Slic3r slicing software (1.3.1-dev, Open-source platform). The design of experiment (DOE) for printer parameters are presented in Table 1 along with fill angles of each specimen.

Table 1. Parameters of the 3D printing process.

\begin{tabular}{cc}
\hline Printing Parameter & Value \\
\hline Nozzle Diameter, $\mathrm{mm}$ & 0.4 \\
Layer Height, $\mathrm{mm}$ & 0.1 \\
Fill Pattern & Rectilinear \\
Fill Percentage, $\%$ & 100 \\
Perimeters Speed, $\mathrm{mm} / \mathrm{s}$ & 25 \\
External Perimeters Speed, $\mathrm{mm} / \mathrm{s}$ & 12.5 \\
Infill Speed, $\mathrm{mm} / \mathrm{s}$ & 40 \\
First Layer Temperature, ${ }^{\circ} \mathrm{C}$ & 240 \\
Other Layers Temperature, ${ }^{\circ} \mathrm{C}$ & 230 \\
Bed Temperature, ${ }^{\circ} \mathrm{C}$ & 80 \\
Number of Layers & 40 \\
Fill Angles, ${ }^{\circ}$ & $45,55,555^{\prime}, 60,90$ \\
\hline
\end{tabular}

All test samples were printed at XY layer orientation, specimens GCODE for 45-55-60-90 degree fill angles were created in Slic3r software (1.3.1-dev, Open-source platform) with a standardized translation vector of $90^{\circ}$ between combined layers. The detailed scheme of layers' deposition in each variant is presented in Figure 2. 


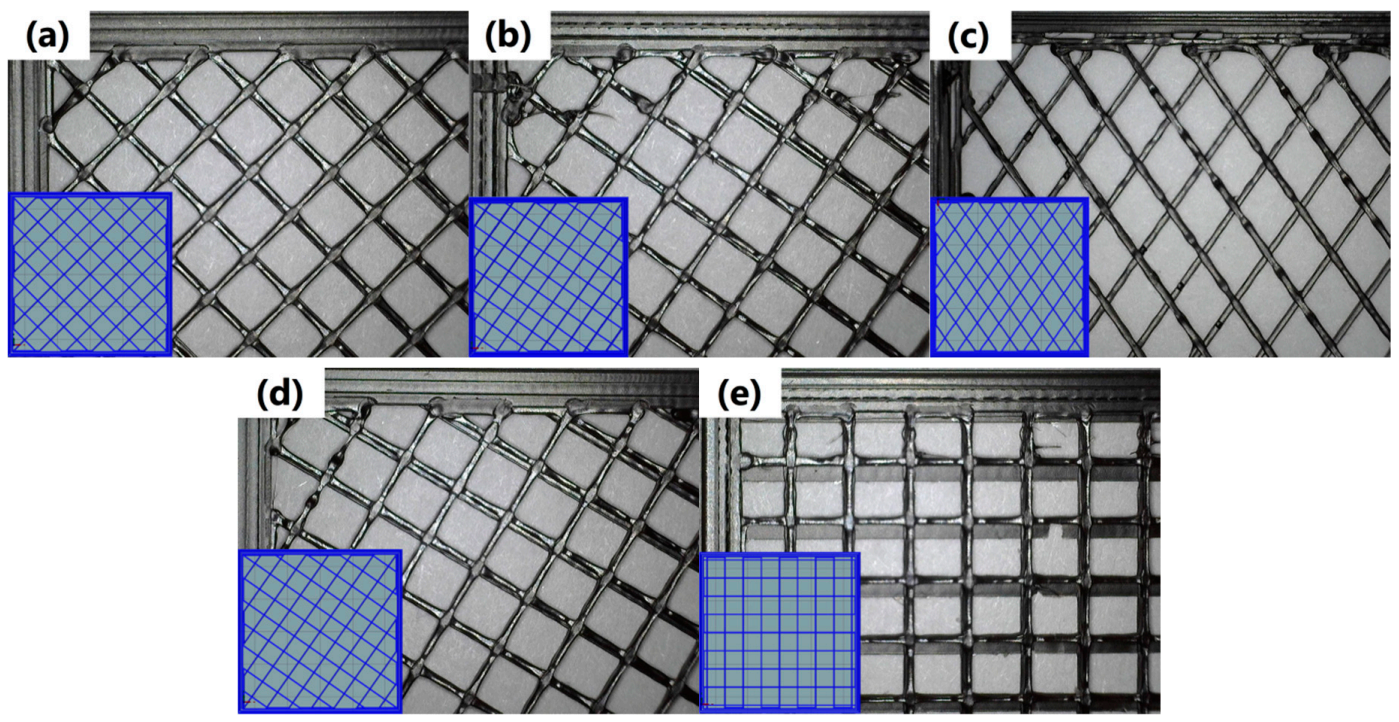

Figure 2. Scheme of layers' deposition during 3D printing of samples (at 20\% infill percentage) for following infill angles: (a) $45^{\circ}$, (b) $55^{\circ}$, (c) $55^{\circ}$, (d) $60^{\circ}$ and (e) $90^{\circ}$.

The only exceptions were samples obtained for $55^{\circ}$ infill angle, which were redesigned in comparison to the original $55^{\circ}$ arrangement. In redesigned specimens, layers were deposited at $55^{\circ}$ and $-55^{\circ}$ to the longitudinal direction, which resulted in an increase of the angle between the following layers from $90^{\circ}$ to $110^{\circ}$. As mentioned above, this configuration of infill was applied based on the manufacturing of filament-wound pipes. Analysis of the "conventional" $55^{\circ}$ raster angle configuration was aimed to compare the influence of mutual arrangement of the following layers on the mechanical performance of obtained samples and to compare a "conventional" approach to the innovative one, based on filament-wound pipes.

Injection-molded samples were obtained using the Arburg type Allrounder 270-210-500 injection-molding machine (Arburg, Loßburg, Germany). Specimens were prepared according to ASTM 527 standard, with the cross-section of the measurement part equal $40 \mathrm{~mm}^{2}$. The machine is equipped with a Priamus injection process controller (Priamus, Schaffhausen, Switzerland). ARBURG Allrounder characteristics: screw diameter: $25 \mathrm{~mm}$, injection pressure: $\max 1400 \mathrm{bar}$, clamping force: $500 \mathrm{kN}$. Sample injection parameters: temperature of the polymer melt: $230{ }^{\circ} \mathrm{C} \pm 2{ }^{\circ} \mathrm{C}$, form temperature: $-40{ }^{\circ} \mathrm{C} \pm 1{ }^{\circ} \mathrm{C}$, injection speed: $190 \mathrm{~mm} / \mathrm{s}$, cycle period: $60 \mathrm{~s}$, injection pressure: $500 \mathrm{bar}$, clamping pressure: 350 bar.

\subsection{Measurements}

The tensile strength, elongation at break, and elastic modulus were estimated following the PN-EN ISO 527 standard. It is one of the most common mechanical tests performed on a dogbone or dumbbell specimen. The geometry of the test sample allows for a wide section to be easily gripped while the elongation testing and measuring the load carried by a specimen is performed. Collected data about load and deflection allows generating a stress-strain curve which can be used to extract a variety of tensile properties [19]. Tensile tests were performed using the Instron 4465H 1937 tensile testing machine (Instron; Norwood, CO, USA) with elongation head and an extensometer. Tensile tests were performed at a constant speed of $1 \mathrm{~mm} / \mathrm{min}$ (for Young's modulus) and $50 \mathrm{~mm} / \mathrm{min}$ (tensile strength and elongation at break). Five samples were analyzed for each specimen.

The Charpy impact test has been conducted in accordance with PN-EN ISO 179-1:2010 standard. The test has been performed on JSP Maskinfabrik A/S Hammel Pendulum 12959 (SCITEQ A/S; Hinnerup, Denmark) with a pendulum of potential energy 7.5 J. During testing, pendulum is raised to a measured point and after releasing gains speed as it swings toward a mounted specimen of test 
plastic. At the moment of their contact pendulum loses energy to break the plastic specimen. The lost energy is equated with the energy absorbed by the test sample during the breaking process [19].

The dynamic mechanical analysis was performed using the DMA Q800 TA Instruments apparatus (TA Instruments; New Castle, DE, USA). Samples cut to the dimensions of $40 \times 10 \times 2 \mathrm{~mm}$ were loaded with a variable sinusoidal deformation force in the single cantilever bending mode at the frequency of $1 \mathrm{~Hz}$ under the temperature rising rate of $4{ }^{\circ} \mathrm{C} / \mathrm{min}$ within the temperature range between 20 and 180 ${ }^{\circ} \mathrm{C}$.

Results of the static and dynamic mechanical analysis were used to calculate the brittleness of investigated materials, according to the following Equation (1) presented by Brostow et al. [20]:

$$
B=1 /\left(\varepsilon_{b} \times E^{\prime}\right)
$$

where: $B$-brittleness, $10^{10} \% \cdot \mathrm{Pa}$; $\varepsilon_{b}$ —elongation at break, \%; $E^{\prime}$ —storage modulus at $25^{\circ} \mathrm{C}, \mathrm{MPa}$.

\section{Results and Discussion}

In Table 2, there are presented values of mechanical properties of 3D printed samples and compared to those of injection-molded materials. As can be noticed, injection-molded samples are characterized with significantly improved mechanical performance comparing to 3D printed ones. Such an effect is related to the structure of the obtained materials. In Figure 3, fracture areas obtained after tensile tests are presented for specimens prepared by both methods. It can be seen that injection-molded samples show homogenous, concise structure, in contrast to the 3D printed specimens. It is related to the characteristics of the process, especially to high pressure applied during the forming of material, which guarantees precise filling of a mold cavity with polymer melt [21]. For better understanding, in Table 2, there are also presented values of materials' porosity, which were determined according to the following Equation (2):

$$
P=\left(\rho_{i n j}-\rho_{3 D}\right) / \rho_{\text {inj }} \times 100 \%
$$

where: $P$-porosity, \%; $\rho_{i n j}$-density of the injection-molded sample, $\mathrm{g} / \mathrm{cm}^{3} ; \rho_{3 D}$-density of the 3D printed sample, $\mathrm{g} / \mathrm{cm}^{3}$.

It can be seen that 3D printed samples are characterized with significantly higher porosity, implicating differences in density, which has a very significant influence on tensile strength of material [22].

Moreover, due to differences in the alignment pattern of filament during 3D printing of specimens, hence different porosity, the orientation of infill has a significant impact on the mechanical performance of the material. Generally, very similar mechanical performance and its dependence on infill angle in the case of 3D printed ABS samples were noted by other researchers [23].

3D printed materials showed the best tensile properties for default $45^{\circ}$ infill angle, accounting for $94.5 \%, 85.3 \%$ and $85.3 \%$ of the strength of injection molded samples, for $1 \mathrm{~W}, 2 \mathrm{~W}$, and $1 \mathrm{~B}$ filaments, respectively. It may be because specimens with a $45^{\circ}$ angle have alternately stacked layers with the optimal orientation to loading direction in the specimen for tension tests. Results differed in $55^{\circ \circ}$ sample case, where overall properties were noticeably (except $2 \mathrm{~W}$ specimen) worse in a tensile test. Such poor tensile performance was caused by the highest porosity of samples for this infill configuration. 
Table 2. Mechanical properties of 3D printed samples depending on used material and infill angle.

\begin{tabular}{|c|c|c|c|c|c|c|c|c|c|}
\hline Material & Infill Angle & Porosity, \% & $\begin{array}{c}\text { Tensile } \\
\text { Strength, } \\
\mathrm{MPa}\end{array}$ & $\begin{array}{c}\text { Elongation at } \\
\text { Break, \% }\end{array}$ & $\begin{array}{c}\text { Young's } \\
\text { Modulus, } \\
\text { Mpa }\end{array}$ & $\begin{array}{c}\text { Toughness, } \\
\mathrm{J} / \mathrm{cm}^{3}\end{array}$ & $\begin{array}{c}\text { Charpy } \\
\text { Impact } \\
\text { Strength, } \\
\mathrm{J} / \mathrm{cm}^{2}\end{array}$ & $\begin{array}{c}\mathrm{E}^{\prime} \text { at } 25^{\circ} \mathrm{C} \\
\mathrm{Mpa}\end{array}$ & $\begin{array}{c}\text { Brittleness, } \\
10^{10} \% \cdot P a\end{array}$ \\
\hline \multirow{6}{*}{$1 \mathrm{~W}$} & 45 & $7.48 \pm 0.23$ & $37.9 \pm 0.2$ & $7.4 \pm 1.0$ & $2486 \pm 51$ & $196 \pm 5$ & $2.1 \pm 0.2$ & 1475.1 & 0.9161 \\
\hline & 55 & $7.58 \pm 0.04$ & $37.6 \pm 0.4$ & $5.0 \pm 0.7$ & $2432 \pm 37$ & $139 \pm 21$ & $2.3 \pm 0.1$ & 1587.6 & 1.2646 \\
\hline & $55^{\prime}$ & $10.33 \pm 0.18$ & $31.9 \pm 0.5$ & $4.1 \pm 1.7$ & $2112 \pm 19$ & $118 \pm 19$ & $2.3 \pm 0.1$ & 1392.4 & 1.7517 \\
\hline & 60 & $8.89 \pm 0.22$ & $32.0 \pm 0.7$ & $3.9 \pm 0.5$ & $2196 \pm 5$ & $106 \pm 11$ & $1.9 \pm 0.1$ & 1424.9 & 1.7995 \\
\hline & 90 & $8.70 \pm 0.93$ & $34.4 \pm 0.6$ & $3.5 \pm 0.6$ & $2336 \pm 41$ & $85 \pm 8$ & $1.4 \pm 0.1$ & 1482.6 & 1.9271 \\
\hline & IM & - & $40.1 \pm 0.1$ & $9.6 \pm 0.4$ & $2667 \pm 42$ & $312 \pm 41$ & $6.3 \pm 0.6$ & - & - \\
\hline \multirow{6}{*}{$2 \mathrm{~W}$} & 45 & $6.08 \pm 0.10$ & $41.7 \pm 0.4$ & $5.8 \pm 0.2$ & $2348 \pm 45$ & $181 \pm 7$ & $2.6 \pm 0.2$ & 1607.1 & 1.0728 \\
\hline & 55 & $7.22 \pm 0.29$ & $41.2 \pm 0.3$ & $5.4 \pm 0.5$ & $2327 \pm 53$ & $153 \pm 7$ & $2.7 \pm 0.2$ & 1609.8 & 1.1504 \\
\hline & $55^{\prime}$ & $9.86 \pm 0.98$ & $41.2 \pm 0.3$ & $3.4 \pm 0.3$ & $2329 \pm 64$ & $98 \pm 14$ & $2.8 \pm 0.1$ & 1657.7 & 1.7743 \\
\hline & 60 & $7.96 \pm 0.40$ & $39.8 \pm 0.5$ & $3.5 \pm 0.2$ & $2329 \pm 68$ & $91 \pm 5$ & $2.2 \pm 0.2$ & 1613.6 & 1.7707 \\
\hline & 90 & $8.33 \pm 0.31$ & $39.2 \pm 0.4$ & $3.6 \pm 0.4$ & $2297 \pm 57$ & $86 \pm 13$ & $1.9 \pm 0.4$ & 1480.6 & 1.8761 \\
\hline & $\mathrm{IM}$ & - & $48.9 \pm 0.6$ & $8.7 \pm 0.4$ & $2747 \pm 105$ & $318 \pm 16$ & $6.3 \pm 0.7$ & - & - \\
\hline \multirow{6}{*}{ 1B } & 45 & $6.22 \pm 0.13$ & $37.2 \pm 0.5$ & $5.7 \pm 0.9$ & $2353 \pm 50$ & $149 \pm 24$ & $2.1 \pm 0.2$ & 1440.4 & 1.2180 \\
\hline & 55 & $6.61 \pm 0.34$ & $36.9 \pm 0.5$ & $5.2 \pm 0.8$ & $2369 \pm 37$ & $132 \pm 14$ & $2.3 \pm 0.1$ & 1444.0 & 1.3317 \\
\hline & $55^{\prime}$ & $9.80 \pm 0.18$ & $33.9 \pm 0.3$ & $3.7 \pm 0.6$ & $2181 \pm 43$ & $96 \pm 12$ & $2.4 \pm 0.2$ & 1338.7 & 2.0189 \\
\hline & 60 & $8.45 \pm 0.88$ & $35.5 \pm 0.5$ & $3.7 \pm 0.5$ & $2346 \pm 95$ & $91 \pm 16$ & $1.7 \pm 0.1$ & 1500.1 & 1.8017 \\
\hline & 90 & $8.11 \pm 0.84$ & $33.3 \pm 0.7$ & $3.4 \pm 0.2$ & $2203 \pm 77$ & $79 \pm 7$ & $1.3 \pm 0.1$ & 1526.9 & 1.9263 \\
\hline & IM & - & $40.9 \pm 0.5$ & $9.2 \pm 1.7$ & $2544 \pm 143$ & $277 \pm 31$ & $6.1 \pm 0.9$ & - & - \\
\hline
\end{tabular}



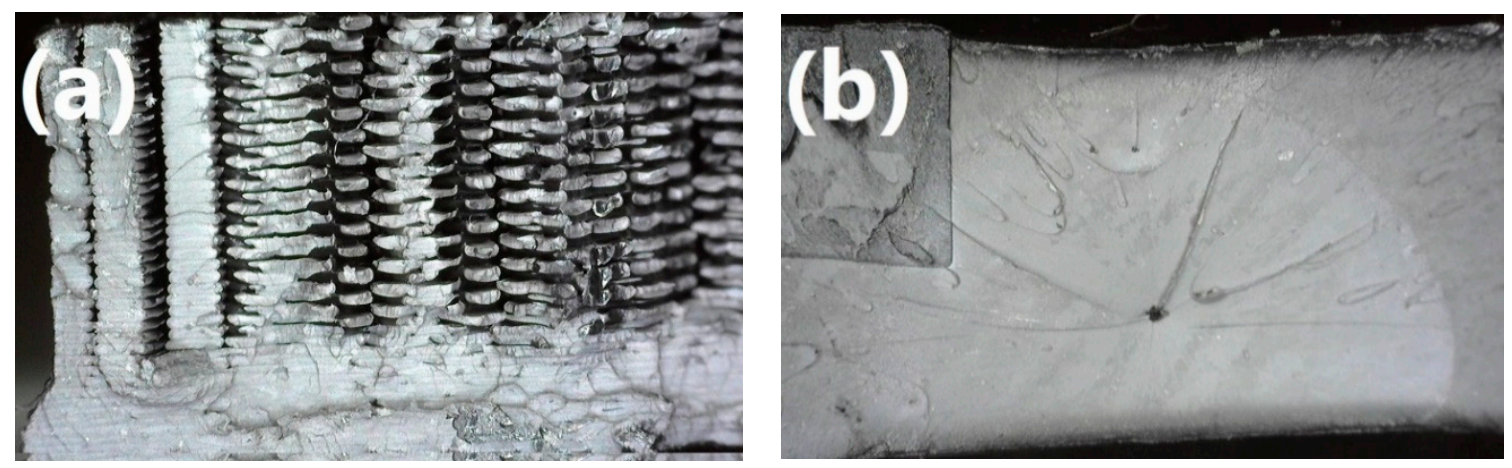

Figure 3. Fracture areas obtained after tensile tests for (a) 3D printed sample with infill angle of $55^{\circ}$ and (b) injection molded sample.

Elongation at break is decreasing with the increase of infill angle, which is related to the mechanisms occurring during tension on the molecular level. As the polymer sample is subjected to uniaxial tension, macromolecular chains are rearranging and aligning in the direction of tension. In the ideal situation and appropriately low strain rate, chains are finally reaching their maximum length before the break. In reality, such a situation is impossible due to entanglements and branching of polymer chains. Nevertheless, when chains are originally aligned closer to the direction of tension, they require lower strain to reach their maximum length, which affects the value of elongation at break. On the other hand, when polymer macromolecular chains are aligned perpendicularly to the direction of tension, they are often unable to rearrange. In such a situation, when adhesion between particular chains is significantly weaker than the strength of the chain itself, delamination may occur [24]. It is especially likely for a $90^{\circ}$ infill angle when every second layer is deposited perpendicularly to the direction of strain applied during tensile tests.

In Figure 4, an exemplary stress-strain curve for 1W45 sample visualizing method of calculating toughness by integrating the stress-strain curve. As a combination of material strength and elongation at break, toughness is a measure of the energy that can be absorbed or dispersed by the material before it cracks. The values of toughness for 3D printed samples are presented in Table 2. Ideally, tough material should be able to withstand high stress for possibly the highest elongation. It can be seen that the best combination of strength and ductility was observed for samples with a $45^{\circ}$ infill angle. The lowest toughness values were observed for a $90^{\circ}$ fill angle, which can be associated with the very low strength of every second layer, in which infill was deposited perpendicularly to the tension direction and low elongation of fibers parallel to tension direction. In general, the drop of toughness with the increase of infill angle can be observed, which is strictly associated with the decrease of elongation at break.

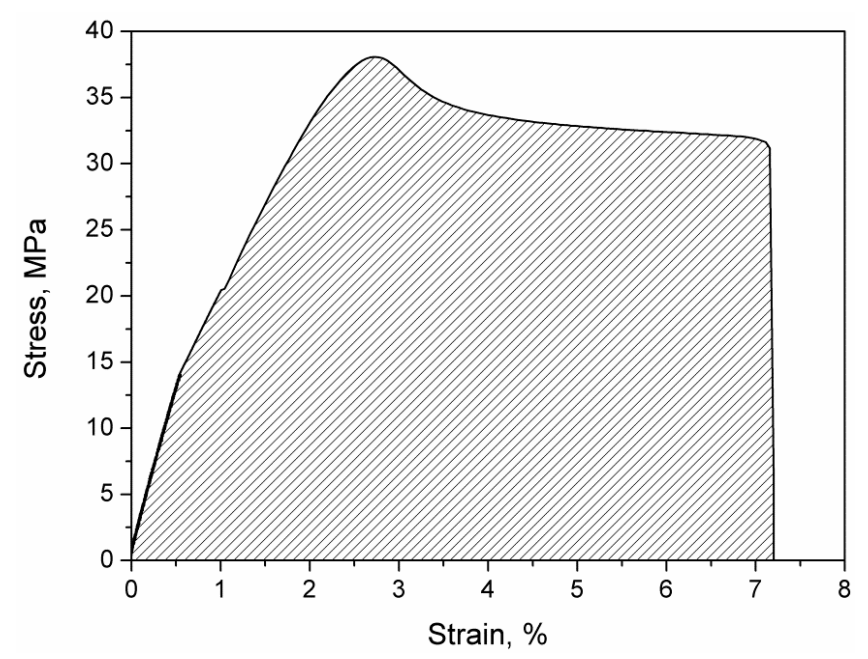

Figure 4. Exemplary stress-strain curve for the 1W45 sample. 
Figure 5 shows the dependence between toughness and brittleness of prepared samples. As mentioned above, brittleness was calculated from the results of static and dynamic mechanical tests following Equation (1) proposed by Brostow et al. [20]. Brittleness was determined as a combination of storage modulus and elongation at break. Materials characterized by a low value of this parameter need to be able to withstand possibly high stress at the possibly widest range of strains. Therefore, low brittleness requires simultaneously high modulus and high elongation at break, posing it as an antagonist of toughness. The significance of the relationship between elongation at break and brittleness was earlier emphasized by other researchers [25,26]. Brostow et al. [27] presented the Equation (3), which can be used to mathematically link brittleness and toughness:

$$
\tau=(b+c B) /(1+a B)
$$

where: $\tau$ stands for toughness, $B$ stands for brittleness, and $a, b$, and $c$ are constants.
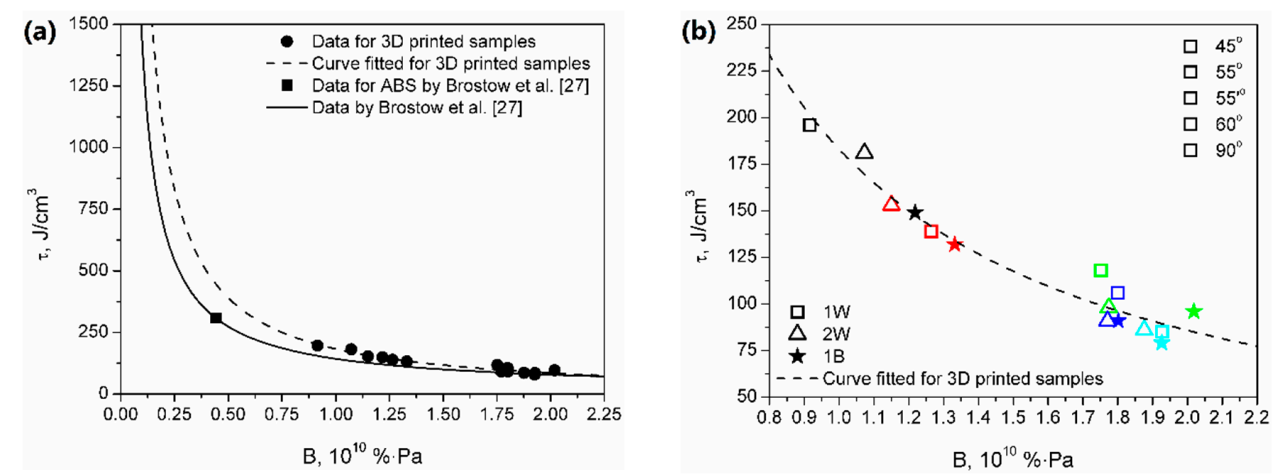

Figure 5. Relationship between toughness and brittleness for analyzed materials. (a) Comparison with literature data by Brostow et al. (26), (b) Detailed data for 3D printed samples.

The formula was developed based on the data obtained for various materials including metals and multiple polymers. Based on their data, authors determined the values of "universal" constants as follows: $a=-111, b=-14,102$ and $c=-1640$, with a coefficient of determination $R^{2}=0.934$. The proposed formula can also be expressed as an exponential function, in the following form Equation (4):

$$
\tau=d B^{e}
$$

where: $\tau, B$ has the same meaning as in Equation (3) and $d$ and $e$ are other constant parameters.

The values of $d$ and $e$ parameters for their data are 178.380 and -0.984 , respectively, while for the curve fitted for 3D printed specimens are 183.110 and -1.092 , respectively. Moreover, in Figure 5, a data point for ABS according to the calculations of Brostow et al. is presented [27]. It can be seen that 3D printed samples show lower values of toughness and higher brittleness than materials studied by Brostow et al. [27]. Such an effect is often observed during the comparison of 3D printing with conventional processing techniques, such as injection molding. It is associated with the characteristics of the FDM technique, based on layer-by-layer deposition of material, where the following layers are not connected by polymer macromolecules, simultaneously reducing cohesion of specimen [28]. Moreover, as it can be seen in Figure 3 showing a fracture area after tensile tests, 3D printed samples are characterized with significantly improved porosity, which also reduces the mechanical performance of polymeric materials. Nevertheless, it can be seen that the differences between data curves based on literature data and properties of 3D printed samples are not very significant, which suggests that the model developed by Brostow et al. [27] could be considered valid for the analysis of materials obtained with FDM.

Similar to toughness, impact strength determined during Charpy impact tests is a measure of the amount of energy needed to destroy the specimen. The difference between these two parameters 
is associated with the magnitude of strain rate [29]. Tensile toughness is characterizing materials' resistance in lower strain rate situations comparing to impact strength. The difference in mechanisms of these two tests is mirrored in the lack of correlation between tensile toughness and impact strength.

Generally, in the case of Charpy impact strength, samples obtained with injection molding are noticeably stronger comparing to 3D printed (additively manufactured samples were able to obtain $(36.51 \%-1 \mathrm{~W}, 44.44 \%-2 \mathrm{~W}, 39.34 \%-1 \mathrm{~B})$ of injection molding samples), which is the result of significantly more efficient stress transfer mechanisms in the molded sample. Such an effect is related to the fact that, in 3D printed samples, different threads of filament are not bonded together, only deposited next to each other. Therefore, no macromolecular chains are interpenetrating various layers of printed specimens, which facilitates the "delamination" of a sample when stress is applied. Moreover, during injection molding, high pressure is applied to the molten polymer, to precisely fill the mold cavity, which results in a higher density of injection molded samples, comparing to 3D printed ones $\left(1.026-1.033 \mathrm{~g} / \mathrm{cm}^{3}\right.$ vs. $\left.0.923-0.969 \mathrm{~g} / \mathrm{cm}^{3}\right)$. Such results implicate the presence of porosity in 3D printed specimens (see Figure 3), which has a noticeable influence on the mechanical performance of prints because, despite using $100 \%$ infill, the structure of 3D printed specimen is heterogeneous.

Brostow and Hagg Lobland [30] analyzed the relationship between materials' brittleness and impact performance since these two properties are closely related to each other. They developed the Equation (5), which is relating Charpy impact strength to material's brittleness:

$$
I_{c}=(a+1) /(\tanh (b B))
$$

where: $I_{\mathcal{C}}$ stands for Charpy impact strength, $B$ stands for brittleness, and $a$ and $b$ are constants.

For data presented by Brostow and Hagg Lobland [30], values of constants are $a=-0.640$ and $b=1.630$, and, again, it can be seen that dependence between mechanical properties of 3D printed samples differs from literature data (see Figure 6). However, it can be seen that, surprisingly, data points for investigated specimens lay above the literature curve. It can be concluded that, for a similar level of brittleness, 3D printed samples are characterized with higher than expected impact strength. Such an effect can be associated with characteristics of the 3D printed samples and their morphology. Layer-by-layer deposition of material during printing and proper arrangement of polymer fibers may noticeably enhance the impact performance of the material, which is often used in the designing of laminate structures [31]. As mentioned above, this phenomenon is taken into account during the manufacturing of filament-wound pipes, and just as in the case of these materials, for 3D printed samples, the best impact performance was noted for the fiber arrangement corresponding to $55^{\circ}$ winding angle in pipes (see Table 2) [32].

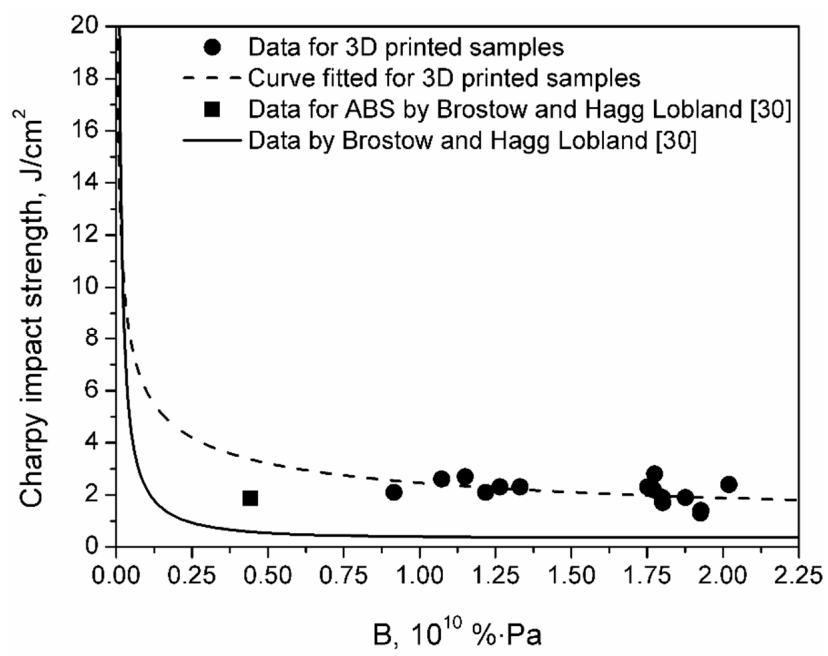

Figure 6. Relationship between Charpy impact strength and brittleness for analyzed materials and comparison with literature data. 


\section{Conclusions}

The presented research paper was aimed at investigation of the impact of raster angle and $3 \mathrm{D}$ printing configuration on the static and dynamic mechanical performance of different ABS samples. Performed tests confirmed the noticeable influence of this parameter on the mechanical properties of resulting prints. Moreover, except conventionally investigated raster angles of $45^{\circ}$, $60^{\circ}$, and $90^{\circ}$, we investigated two configurations based on an angle of $55^{\circ}$-first was "conventional", with orthogonal following layers, while the second was based on optimal winding angle applied during the manufacturing of filament-wound pipes. To the best of our knowledge, such configuration, which provides exceptional properties for pipes, was analyzed in 3D printing for the first time. Although it did not result in enhancement of tensile performance of prints, it provided the highest values of Charpy impact strength for all three types of analyzed ABS materials, despite the highest porosity of the structure exceeding even $10 \%$ compared to injection-molded samples. Such results confirm the benefits observed for filament-wound pipes when the analyzed mutual arrangement of the following layers is applied.

Because of the relatively high values of materials' porosity, resulting from the characteristics of the FDM process and lack of interpenetrating macromolecular chains between particular layers deposited during printing, 3D printed samples showed significant values of brittleness. Comparison with literature data indicated that FDM still cannot be considered as a full-fledged alternative for the injection molding when it comes to the mechanical performance of resulting products. On the other hand, due to some similarities between layer-by-layer deposition of material during FDM printing and manufacturing of laminates, prepared 3D prints showed surprisingly high values of Charpy impact strength, considering their brittleness, overtaking even injection-molded ABS. To sum up, the presented results prove that, despite extensive research works related to the FDM technology, there is still a lot of investigation required for a proper understanding of this process. Further research studies should be more focused on the analysis of overall mechanical performance, not only the most popular tensile and flexural properties. Such an approach would enable tailoring of the performance of final products, which is often emphasized in the case of 3D printing.

Author Contributions: Conceptualization, M.G. and A.K.; methodology, A.H.; software, M.G.; validation, A.H. and P.K.; formal analysis, A.H. and P.K.; investigation, M.G., A.H. and P.K.; resources, M.G.; writing-original draft preparation, M.G. and A.H.; writing—review and editing, A.H. and A.K.; visualization, A.H.; supervision, A.K.; project administration, M.G.; funding acquisition, M.G. and A.K. All authors have read and agreed to the published version of the manuscript.

Funding: This research was funded by the Central Mining Institute in the frame of Statutory Work No. 10157028-160.

Conflicts of Interest: The authors declare no conflict of interest.

\section{References}

1. Fafenrot, S.; Grimmelsmann, N.; Wortmann, M.; Ehrmann, A. Three-dimensional (3D) printing of polymer-metal hybrid materials by fused deposition modeling. Materials 2017, 10, 1199. [CrossRef] [PubMed]

2. Galeta, T.; Raos, P.; Stojšić, J.; Pakši, I. Influence of structure on mechanical properties of 3D printed objects. Procedia Eng. 2016, 149, 100-104. [CrossRef]

3. Travieso-Rodriguez, J.A.; Jerez-Mesa, R.; Llumà, J.; Traver-Ramos, O.; Gomez-Gras, G.; Roa Rovira, J.J. Mechanical properties of 3D-printing polylactic acid parts subjected to bending stress and fatigue testing. Materials 2019, 12, 3859. [CrossRef] [PubMed]

4. Kim, H.; Park, E.; Kim, S.; Park, B.; Kim, N.; Lee, S. Experimental study on mechanical properties of singleand dual-material 3D printed products. Procedia Manuf. 2017, 10, 887-897. [CrossRef]

5. Wang, X.; Jiang, M.; Zhou, Z.; Gou, J.; Hui, D. 3D printing of polymer matrix composites: A review and prospective. Compos. Part B Eng. 2017, 110, 442-458. [CrossRef] 
6. Wang, Y.T.; Yeh, Y.T. Effect of print angle on mechanical properties of FDM 3D structures printed with POM material. In Innovative Design and Development Practices in Aerospace and Automotive Engineering; Bajpai, R.P., Chandrasekhar, U., Eds.; Springer: Singapore, 2017; pp. 157-167. [CrossRef]

7. Farbman, D.; McCoy, C. Materials testing of 3D printed ABS and PLA samples to guide mechanical design. In Proceedings of the ASME 2016 11th International Manufacturing Science and Engineering Conference, Blacksburg, VA, USA, 27 June-1 July 2016. [CrossRef]

8. Somireddy, M.; Czekanski, A. Mechanical characterization of additively manufactured parts by FE modeling of mesostructure mechanical characterization of additively manufactured parts by FE modeling of mesostructure. J. Manuf. Mater. Process. 2017, 12, 18. [CrossRef]

9. Quanjin, M.; Rejab, M.R.M.; Kaige, J.; Idris, M.S.; Harith, M.N. Filament winding technique, experiment and simulation analysis on tubular structure. IOP Conf. Ser. Mater. Sci. Eng. 2018, 342, 012029. [CrossRef]

10. Reza Khoshravan Azar, M.; Emami Satellou, A.A.; Shishesaz, M.; Salavati, B. Calculating the optimum angle of filament-wound pipes in natural gas transmission pipelines using approximation methods. J. Press. Vessel Technol. 2013, 135, 021702. [CrossRef]

11. Arikan, H. Failure analysis of $\left( \pm 55^{\circ}\right) 3$ filament wound composite pipes with an inclined surface crack under static internal pressure. Compos. Struct. 2010, 92, 182-187. [CrossRef]

12. Popescu, D.; Zapciu, A.; Amza, C.; Baciu, F.; Marinescu, R. FDM process parameters influence over the mechanical properties of polymer specimens: A review. Polym. Test. 2018, 69, 157-166. [CrossRef]

13. Rousseau, J.; Perreux, D.; Verdière, N. The influence of winding patterns on the damage behaviour of filament-wound pipes. Compos. Sci. Technol. 1999, 59, 1439-1449. [CrossRef]

14. Rajpurohit, S.R.; Dave, H.K. Effect of process parameters on tensile strength of FDM printed PLA part. Rapid Prototyp. J. 2018, 24, 1317-1324. [CrossRef]

15. Wu, W.; Geng, P.; Li, G.; Zhao, D.; Zhang, H.; Zhao, J. Influence of layer thickness and raster angle on the mechanical properties of 3D-printed PEEK and a comparative mechanical study between PEEK and ABS. Materials 2015, 8, 5834-5846. [CrossRef] [PubMed]

16. Villacres, J.; Nobes, D.; Ayranci, C. Additive manufacturing of shape memory polymers: effects of print orientation and infill percentage on mechanical properties. Rapid Prototyp. J. 2018, 24, 744-751. [CrossRef]

17. Hamed, A.F.; Khalid, Y.A.; Sapuan, S.M.; Hamdan, M.M.; Younis, T.S.; Sahari, B.B. Effects of winding angles on the strength of filament wound composite tubes subjected to different loading modes. Polym. Polym. Compos. 2007, 15, 199-206. [CrossRef]

18. Naseva, S.; Srebrenkoska, V.; Risteska, S.; Stefanovska, M.; Srebrenkoska, S. Mechanical properties of filament wound pipes: Effects of winding angles. Qual. Life 2015, 6, 10-15. [CrossRef]

19. McKeen, L.W. Introduction to plastics and elastomers. In Effect of Temperature and Other Factors on Plastics and Elastomers (Second Edition); McKeen, L.W., Ed.; William Andrew Publisher: Norwich, NY, USA, 2008; pp. 1-39. [CrossRef]

20. Brostow, W.; Hagg Lobland, H.E.; Narkis, M. Sliding wear, viscoelasticity, and brittleness of polymers. J. Mater. Res. 2006, 21, 2422-2428. [CrossRef]

21. Fernandes, C.; Pontes, A.J.; Viana, J.C.; Gaspar-Cunha, A. Modeling and optimization of the injection-molding process: A review. Adv. Polym. Technol. 2016, 37, 429-449. [CrossRef]

22. Fang, H.; Li, B.; Wang, F.; Wang, Y.; Cui, C. The mechanical behaviour of drainage pipeline under traffic load before and after polymer grouting trenchless repairing. Tunn. Undergr. Space Technol. 2018, 74, 185-194. [CrossRef]

23. Álvarez, K.; Lagos, R.F.; Aizpun, M. Investigating the influence of infill percentage on the mechanical properties of fused deposition modelled ABS parts. Ingeniería Investig. 2016, 36, 110-116. [CrossRef]

24. Richter, C.; Schmülling, S.; Ehrmann, A.; Finsterbusch, K. FDM printing of 3D forms with embedded fibrous materials. Appl. Mech. Mater. 2015, 2015, 961-969. [CrossRef]

25. Matsuoka, S. Thermodynamic aspects of brittleness in glassy polymers. In Toughness and Brittleness of Plastics; Deanin, R.D., Crugnola, A.M., Eds.; American Chemical Society: Washington, DC, USA, 1976; pp. 3-7. [CrossRef]

26. Menges, G.; Boden, H.E. Deformation and failure of thermoplastics on impact. In Failure of Plastics; Brostow, W., Corneliussen, R.D., Eds.; Hanser Publishers: Munich, Germany, 1986; p. 179.

27. Brostow, W.; Hagg Lobland, H.E.; Khoja, S. Brittleness and toughness of polymers and other materials. Mater. Lett. 2015, 159, 478-480. [CrossRef] 
28. Caminero, M.A.; Chacón, J.M.; García-Moreno, I.; Reverte, J.M. Interlaminar bonding performance of 3D printed continuous fibre reinforced thermoplastic composites using fused deposition modelling. Polym. Test. 2018, 68, 415-423. [CrossRef]

29. Harding, J.; Wood, E.O.; Campbell, J.D. Tensile testing of materials at impact rates of strain. J. Mech. Eng. Sci. 1960, 2, 88-96. [CrossRef]

30. Brostow, W.; Hagg Lobland, H.E. Brittleness of materials: implications for composites and a relation to impact strength. J. Mater. Sci. 2009, 45, 242-250. [CrossRef]

31. Portella, E.H.; Romanzini, D.; Angrizani, C.C.; Amico, S.C.; Zattera, A.J. Influence of stacking sequence on the mechanical and dynamic mechanical properties of cotton/glass fiber reinforced polyester composites. Mater. Res. 2016, 19, 542-547. [CrossRef]

32. Xing, J.; Geng, P.; Yang, T. Stress and deformation of multiple winding angle hybrid filament-wound thick cylinder under axial loading and internal and external pressure. Compos. Struct. 2015, 131, 868-877. [CrossRef]

C 2020 by the authors. Licensee MDPI, Basel, Switzerland. This article is an open access article distributed under the terms and conditions of the Creative Commons Attribution (CC BY) license (http://creativecommons.org/licenses/by/4.0/). 